This item was submitted to Loughborough's Research Repository by the author.

Items in Figshare are protected by copyright, with all rights reserved, unless otherwise indicated.

\title{
Flexible automatic generation control system for embedded HVDC links
}

PLEASE CITE THE PUBLISHED VERSION

http://dx.doi.org/10.1109/PTC.2015.7232555

PUBLISHER

(c) IEEE

VERSION

AM (Accepted Manuscript)

\section{PUBLISHER STATEMENT}

This work is made available according to the conditions of the Creative Commons Attribution-NonCommercialNoDerivatives 4.0 International (CC BY-NC-ND 4.0) licence. Full details of this licence are available at: https://creativecommons.org/licenses/by-nc-nd/4.0/

\section{LICENCE}

CC BY-NC-ND 4.0

\section{REPOSITORY RECORD}

Gonzalez-Longatt, Francisco M., Anton Steliuk, and Victor H. Hinojosa. 2019. "Flexible Automatic Generation Control System for Embedded HVDC Links". figshare. https://hdl.handle.net/2134/17690. 


\section{Flexible Automatic Generation Control System for Embedded HVDC Links}

\author{
Francisco Gonzalez-Longatt \\ Loughborough University \\ School of Electric, Electronic and \\ Systems Engineering \\ Loughborough, United Kingdom \\ fglongatt@fglongatt.org
}

\author{
Anton Steliuk \\ DMCC Engineering Ltd \\ Peremogy ave., 56, Kyiv, 03056 \\ Donetsk, Ukraine \\ anton.stelyuk@dmcc.com.ua
}

\author{
Víctor Hugo Hinojosa M \\ Federico Santa María Technical \\ University Electrical Energy \\ Department Valparaiso-Chile \\ victor.hinojosa@usm.cl
}

\begin{abstract}
Frequency quality will be maintained as ancillary service instead of utilities, and different qualities in one system may be requested depends on the framework of service. This paper proposes a flexible Automatic Generation Control (AGC) system for embedded HVDC links in order to provide frequency sensitive response and control power interchange.
\end{abstract}

Index Terms-- Automatic generation control, frequency controller, frequency stability, power system, protection scheme, wind turbine generator.

\section{INTRODUCTION}

Future energy systems networks will be completely different to the power systems on nowadays [1], [2]. High and low power converters will be massively deployed in several areas on the electric network [3], [4], [3]: (i) renewable energy from highly variable generators connected over high power converters, (ii) several technologies for energy storage with very different time constants, some of them using power converters as an interface to the grid, and (iii) Pan-European transmission network facilitating the massive integration of large-scale renewable energy sources and the balancing and transportation of electricity based on underwater multi-terminal high voltage direct current transmission. The developments of stronger interconnector and massive integration of offshore wind power in remote location are steadily increasing the demand for more robust, efficient, and reliable grid integration solutions. Multiterminal Voltage source converter (VSC)-based HVDC (MTDC) technology has the potential to increase transmission capacity, system reliability, and electricity market opportunities.

The developments of stronger interconnector and massive integration of offshore wind power in remote location are steadily increasing the demand for more robust, efficient, and reliable grid integration solutions. Multi-terminal Voltage source converter (VSC)-based HVDC (MTDC) technology has the potential to increase transmission capacity, system reliability, and electricity market opportunities.

The integration of VSC-HVDC links into transmission systems has the potential to afford a powerful new tool for controlling both over and under frequency conditions. The high degree of controllability inherent to the active power flow on an HVDC link allows rapid changes to the power flow to be used to counter active power imbalances [5].

Primary frequency control in HVDC has been a hot topic in recent times. Several publications has developed and tested controllers to enable inertial response on HVDC systems [69]. HVDC for primary frequency control has been considered in several publications [10], [11], and the coordinated primary frequency control among non-synchronous systems connected by a multi-terminal high-voltage direct current grid is studied in [12]. Also, the problem of providing frequency control services, including inertia emulation and primary frequency control, from offshore wind farms connected through a MTDC network has been studied in [13]. However, secondary and tertiary frequency control considering HVDC or MTDC systems has deserved a very low attention in recent publications.

This paper proposes a flexible Automatic Generation Control (AGC) system for embedded HVDC link in order to provide frequency sensitive response and control power interchange.

\section{Proposed AGC INCLUding EMBedded HVDC LinK}

The structure of the proposed AGC of the interconnected power system or area is shown in Fig. 1. There are four control levels of the active power and frequency control. The upper system control level is presented by the AGC of the power system. The input signals are the system frequency measurement $f_{\text {meas }}$ in the power, the scheduled power on the interface $\left(P_{\text {tie }}\right)$ and line interchanges (AC lines: $P_{\text {flow }, k}$, and DC lines: $\left.P_{D C, i j}\right)$. 


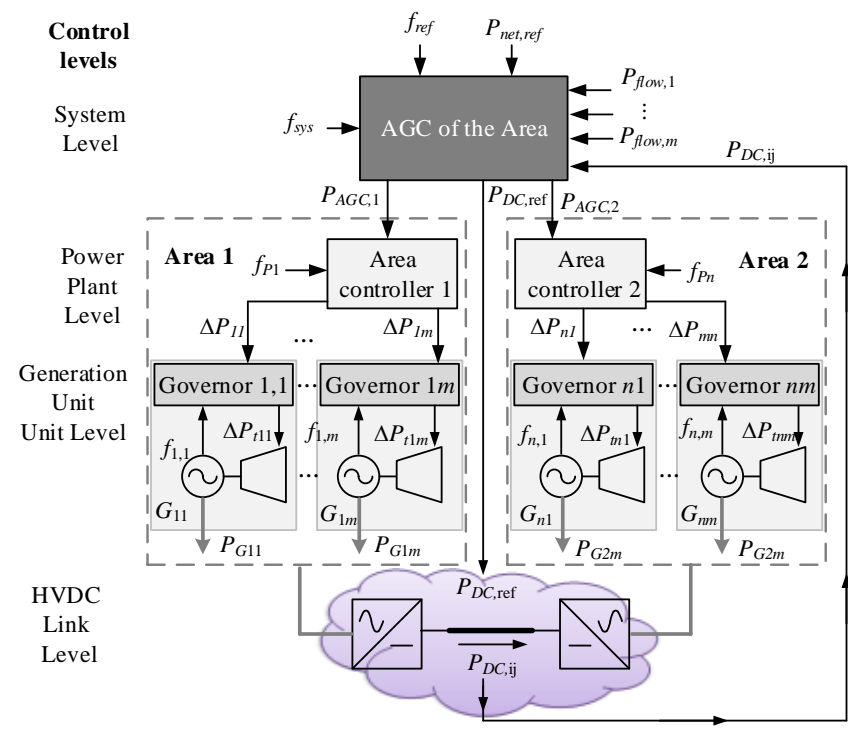

Fig. 1. The structure of the automatic generation control.

Based on tie-line interchanges, the net interchange power $\left(P_{n e t, r e f}\right)$ is calculated as:

$$
P_{n e t, r e f}=\sum_{k=1}^{N_{\text {branches }}} P_{\text {flow }, k}+P_{D C, i j}
$$

In the AGC of the power system (at the system control level) the system frequency deviation $(\Delta f)$ and the changes on the net interchange power $\left(\Delta P_{n e t}\right)$ deviations are defined as:

$$
\begin{aligned}
\Delta f & =f_{\text {sys }}-f_{\text {ref }} \\
\Delta P_{n e t} & =P_{n e t}-P_{n e t, r e f}
\end{aligned}
$$

where: $f_{\text {ref }}$ is a frequency set point value (typically, the rated or nominal frequency), $P_{\text {net.ref }}$ is a net interchange power set point value. The area control error (ACE) is calculated as:

$$
A C E=-\Delta P_{\text {net }}+K_{\text {bias }} \Delta f
$$

where: $K_{\text {bias }}$ is the frequency bias.

In the event of the internal power imbalance of the power system, $A C E$ defines the power to be compensated by the regulating power plants and the HVDC link in order to enforce frequency stabilization between the areas [14]. In the case of the external frequency disturbance due to the different signs of frequency and net interchange power deviations ACE value tends to zero that provides the selectivity of the AGC operation depending on location of the disturbance [14], [15].

The unscheduled active power setting $P_{A G C}$ formed by the proportional-integral (PI) controller on basis of is calculated as follows:

$$
P_{A G C}=K_{P} A C E+K_{I} \int_{t_{1}}^{t_{2}} A C E d t
$$

where: $K_{P}$ is the proportional gain of the PI controller; $K_{I}$ is the integral gain of the PI controller; $t_{1}, t_{2}$ are the integration limits.

As shown in Fig. 1, the control $i$-th AGC control signal $P_{A G C i}$, is transmitted to each regulating power plant, defined according to the participation factor $\alpha_{i}$ of individual power plant in the secondary frequency control:

$$
P_{A G C, i}=\alpha_{i} P_{A G C} \quad i=1,2, \ldots, n
$$

At the power plant control level the signal $P_{P C i}$ formed by the power plant PI controller is calculated as:

$P_{P C i}=K_{P}^{P C}\left(K_{f} \Delta f+\Delta P_{a g c i}-\sum_{j=1}^{m} \Delta P_{T j}\right)+K_{I}^{P C} \int_{t_{1}}^{t_{2}}\left(K_{f} \Delta f+\Delta P_{a g c i}-\sum_{j=1}^{m} \Delta P_{T j}\right) d t$ $i=1,2, \ldots, n$

where: $K_{P}{ }^{P C}$ is the proportional gain of the power plant PI controller; $K_{I}^{P C}$ is the integral gain of the power plant PI controller; $K_{f}$ is the coefficient of frequency correction; and $\Sigma \Delta P_{T_{j}}$ is the sum of the turbine power change of the generating units participating in the secondary frequency control.

The distribution of the control signal $P_{P C i}$ at the $i$-power plant control level is performed in accordance with the participation factors $\beta_{i j}$ of the generating units of $i$-power plant in the secondary frequency control (see Fig. 2):

$$
\Delta P_{i j}=\beta_{i j} P_{P C i} \quad i=1,2, \ldots, n \text { and } j=1,2, \ldots, m
$$

where: $n$ is the number of the regulating power plants; $m$ is the number of the generating units of the $i$-power plant; $\Delta P_{i j}$ is the control signal from the power plant controller. The control signal $\Delta P_{i j . r e f}$ is distributed in such a way that:

$$
P_{P C i}=\sum_{j=1}^{m} \Delta P_{i j} \quad i=1,2, \ldots, n
$$

and

$$
P_{a g c}=\sum_{i=1}^{n} P_{a g c i}=\sum_{i=1}^{n} \sum_{j=1}^{m} \Delta P_{i j} \quad i=1,2, \ldots, n
$$

The calculated control signal $\Delta P_{i j}$ from the power controller is transmitted to the turbine governor of the generating unit (aggregate control level) via the speed changer motor (see Fig. 2). Further, according to the reference control signal $\Delta P_{i j}$, the turbine governor generates a signal of the turbine power change $\Delta P_{t i j}$. Thus, the power changing of the generating units restores the normal frequency and scheduled net interchange power.

Frequency quality will be maintained as ancillary service instead of utilities, and different qualities in one system may be requested depends on the framework of service.

The AGC is a significant control process that operates constantly to balance the generation and load in power systems at a minimum cost. In this paper, the proposed AGC include a control system to provide signals to embedded HVDC links in order to provide frequency sensitive response and control power interchange.

\section{Simulation AND Results}

The IEEE 14 Bus Test Case represents a portion of the American Electric Power System (in the Midwestern USA) as of February, 1962. The original IEEE 14-bus system (as presented on [16], [17]) has been slightly modified, the system has three Power Plants and a boundary has been defined to establish 2 operational areas (Area 1 and Area 2 in Fig. 2). Not depicted in Fig. 2, but included in the system 
model, are generator controllers (IEEE Type 1 speedgoverning model), such as the automatic voltage regulators (SEXS, Simplified Excitation System).

The interface between areas is defined by three overhead transmission lines (OHL 1-5, 1-2/1 and 1-2/2), as consequence the AGC is developed to monitor and control the net power interchange on them.

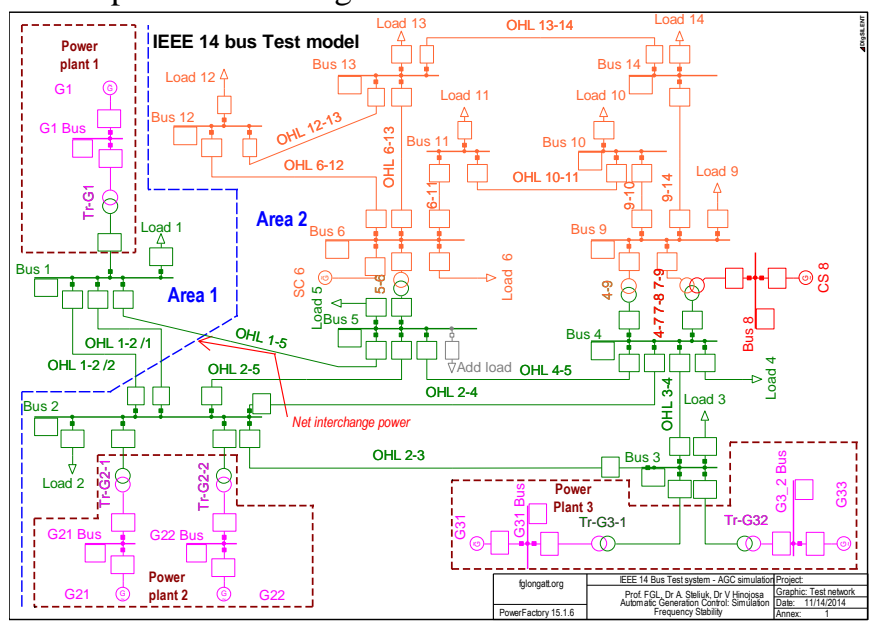

Fig. 2. Modified IEEE 14-bus test system.

The proposed AGC model has been developed using DIgSILENT Simulation Language (DSL).

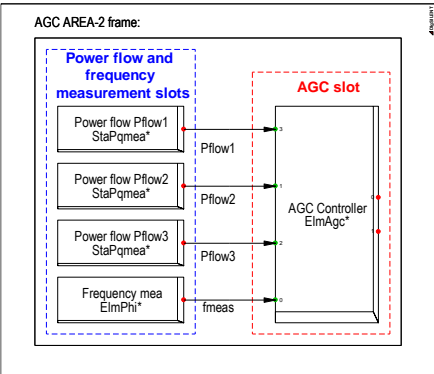

Fig. 3. General frame of the AGC model.

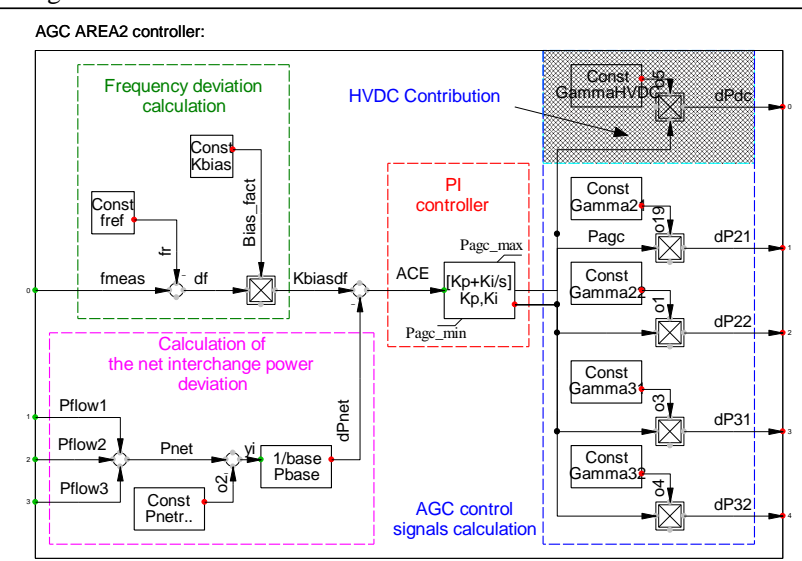

Fig. 5. General frame of the Proposed AGC+HVDC control model

Figs. 6 to 7 illustrate comparative results using classical AGC (CASEI: NO AGC, CASE II: Classic AGC) and the proposed method.

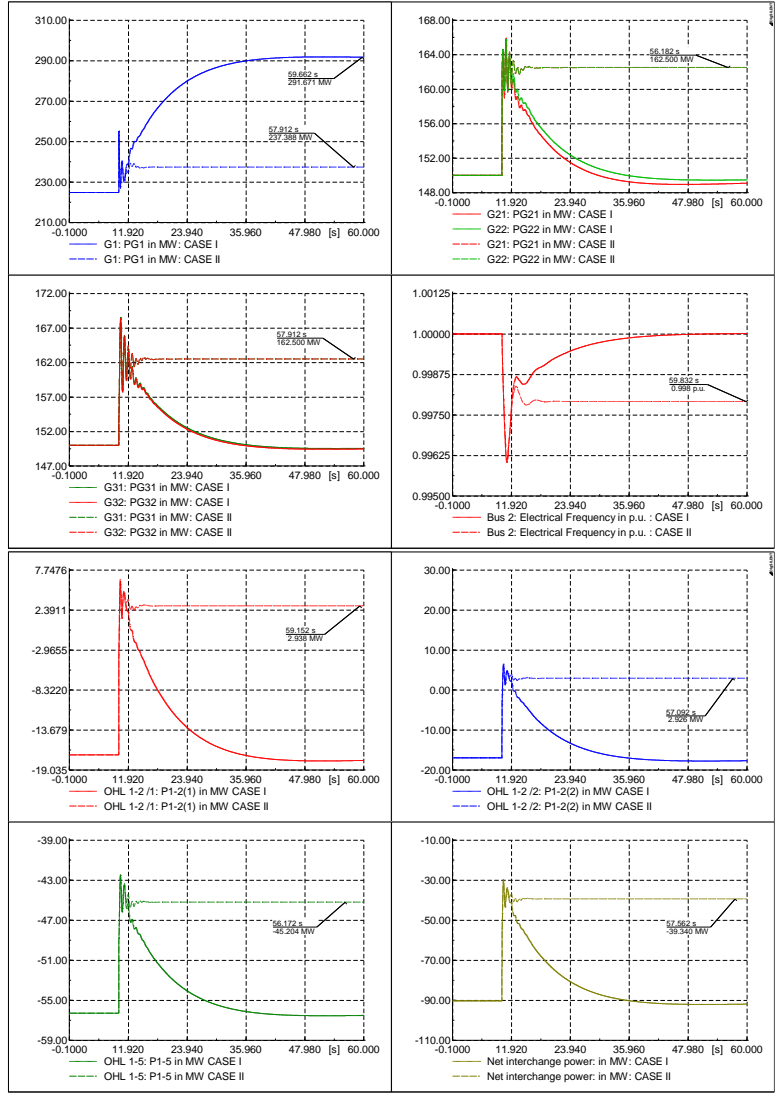

Fig. 6. Results using classical AGC.

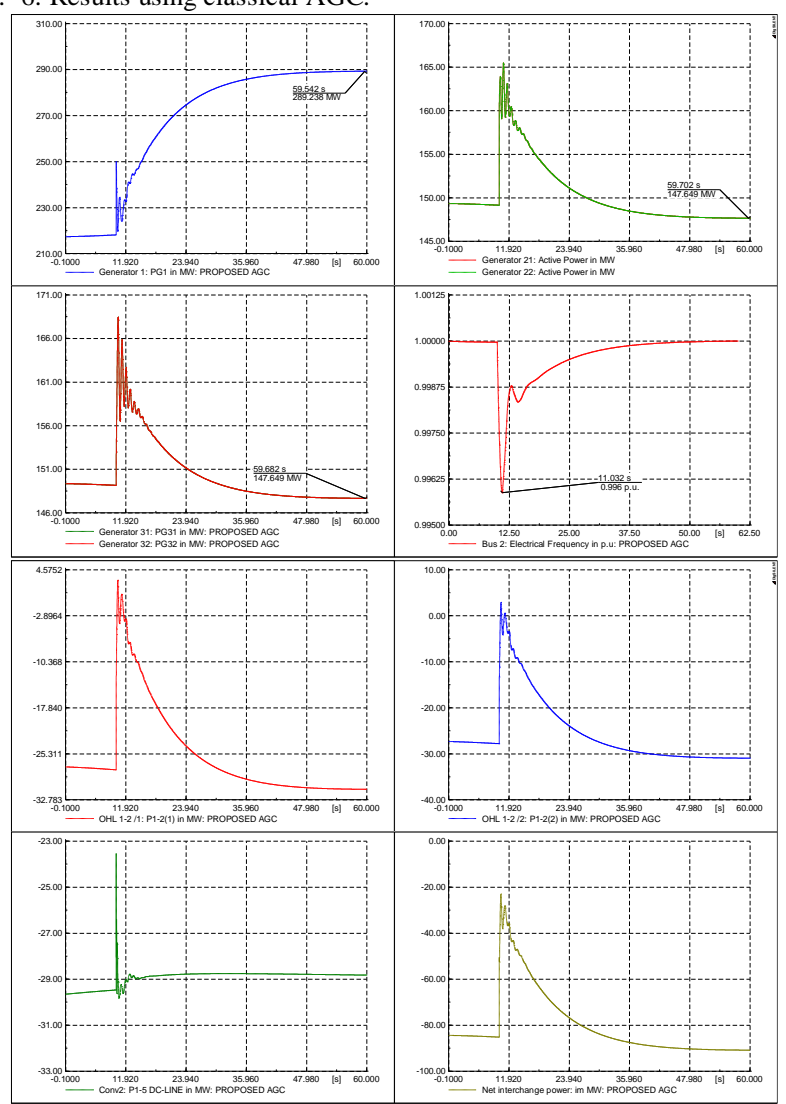

Fig. 7. Results using Proposed AGC. 


\section{REFERENCES}

[1] F. Gonzalez-Longatt, "Frequency Control and Inertial Response Schemes for the Future Power Networks," in Large Scale Renewable Power Generation, J. Hossain and A. Mahmud, Eds., ed: Springer Singapore, 2014, pp. 193-231.

[2] F. Gonzalez-Longatt, "Frequency Control and Inertial Response Schemes for the Future Power Networks," in Advances in Technologies for Generation, Transmission and Storage, Green Energy and Technology Series. vol. VIII, J. Hossain and A. Mahmud, Eds., ed Singapur: Springer-Verlag, 2014, p. 363.

[3] F. Gonzalez-Longatt, "TUTORIAL: Frequency Control and Inertia Response Schemes for the Future Power Networks," presented at the IEEE Inernational Energy Conference and Exhibition, ENERGYCON 2012, Florence, Italy, 2012.

[4] F. Gonzalez-Longatt, "Impact of synthetic inertia from wind power on the protection/control schemes of future power systems: Simulation study," in Developments in Power Systems Protection, 2012. DPSP 2012. 11th International Conference on, 2012, pp. 1-6.

[5] P. Wall, "Online Prediction of the Post-Disturbance Frequency Behaviour of a Power System," Doctor of Philosophy, School of Electrical and Electronic Engineering, The University of Manchester, Manchester, UK, 2013.

[6] Z. Jiebei, C. D. Booth, G. P. Adam, and A. J. Roscoe, "Inertia emulation control of VSC-HVDC transmission system," in Advanced Power System Automation and Protection (APAP), 2011 International Conference on, 2011, pp. 1-6.

[7] Z. Jiebei, C. D. Booth, G. P. Adam, A. J. Roscoe, and C. G. Bright, "Inertia Emulation Control Strategy for VSC-HVDC Transmission Systems," Power Systems, IEEE Transactions on, vol. 28, pp. 12771287, 2013.

[8] Z. Jiebei, J. M. Guerrero, C. D. Booth, Z. Haotian, and G. P. Adam, "A generic Inertia Emulation Controller for multi-terminal VSC-HVDC systems," in Renewable Power Generation Conference (RPG 2013), 2nd IET, 2013, pp. 1-6.

[9] Y. Phulpin, "Communication-Free Inertia and Frequency Control for Wind Generators Connected by an HVDC-Link," Power Systems, IEEE Transactions on, vol. 27, pp. 1136-1137, 2012.

[10] G. Fujita, G. Shirai, and R. Yokoyama, "Automatic generation control for DC-link power system," in Transmission and Distribution Conference and Exhibition 2002: Asia Pacific. IEEE/PES, 2002, pp. 1584-1588 vol.3.

[11] P. F. de Toledo, P. Jiuping, K. Srivastava, W. WeiGuo, and H. Chao, "Case Study of a Multi-Infeed HVDC System," in Power System Technology and IEEE Power India Conference, 2008. POWERCON 2008. Joint International Conference on, 2008, pp. 1-7.

[12] J. Dai, Y. Phulpin, A. Sarlette, and D. Ernst, "Coordinated primary frequency control among non-synchronous systems connected by a multi-terminal high-voltage direct current grid," Generation, Transmission \& Distribution, IET, vol. 6, pp. 99-108, 2012.

[13] B. Silva, C. L. Moreira, L. Seca, Y. Phulpin, and J. A. Peas Lopes, "Provision of Inertial and Primary Frequency Control Services Using Offshore Multiterminal HVDC Networks," Sustainable Energy, IEEE Transactions on, vol. 3, pp. 800-808, 2012.

[14] V. Pavlovsky and A. Steliuk, "Modelling of automatic generation control in power systems," in PowerFactory Applications for Power System Analysis. vol. 1, F. M. Gonzalez-Longatt, Luis Rueda, Jose (Eds.), Ed., First Edition ed: Springer, 2014, p. 582.

[15] P. Kundur, N. J. Balu, and M. G. Lauby, Power system stability and control. New York: McGraw-Hill, 1994.

[16] F. Milano, Power system modelling and scripting. London: Springer, 2010.

[17] F. Gonzalez-Longatt. (2014). IEEE 14 bus Test: Power system test case archive. Available: http://fglongatt.org/OLD/Test Case IEEE 14.html 